\title{
Importância da Aquicultura na Saúde Pública
}

\section{Importance of Aquaculture in Public Health}

\section{Resumo}

A aquicultura é uma importante cadeia produtiva brasileira, que vem se tornando cada vez mais notável no mercado internacional. Entretanto, causa impactos ambientais e riscos para a saúde pública, decorrentes de falhas técnicas e sanitárias que podem ser observadas ao longo de toda cadeia produtiva. Nessa revisão, serão abordados importantes temas relacionados à aquicultura e suas interfaces na preservação ambiental e da saúde das populações, abrangendo importantes zoonoses que vem se tornando emergentes e outros aspectos como a resistência a antibióticos decorrentes da utilização inapropriada pelos produtores.

\section{Summary}

The aquiculture é a important brazilian supply chain, and is coming remarkable at the international markets. However, still causes environmental impacts and risks to the public health from technical and sanitary failures that can be seen along the complete supply chain. On this review, will be addressed important themes related to aquiculture and the interfaces on the environmental and public heath preservation, covering important zoonoses that are coming emergents and other aspects like the resistence to antibiotics arising from the inappropriate use by the producers. 
evido ás mudanças no hábito alimentar das populações, e pelo pescado ser um alimento de excelente fonte protéica, sendo uma das que apresenta maior facilidade de digestão, e rico em ômega 3 e 6, vitaminas e minerais, seu consumo está aumentando,

\section{Keywords}

sendo que os produtos consumidos são oriundos tantos das atividades marinhas como das continentais.

A pesca extrativa no Brasil apresenta limitações para sua expansão, em que ainda ocorre ineficiência econômica e social no uso dos recursos produtivos, decorrentes da sobrepesca, da alocação inapropriada dos insumos produtivos e da falta de uma política apropriada para desenvolvimento e controle da atividade. Dentro desse contexto, a aquicultura permite a adaptação de tecnologias já existentes e o desenvolvimento de novas tecnologias; o aproveitamento dos recursos naturais, a integração racional entre o meio ambiente e a exploração da aquacultura e dos recursos pesqueiros, a diversificação e o aproveitamento dos subprodutos, a possibilidade de sistemas integrados com atividades agrícolas e pecuárias, redução de custos e os riscos atuais da atividade, a qualidade comercial e nutricional dos produtos, e ainda, viabiliza a criação de verdadeiros "bancos de proteína" de custo acessível (QUEIROZ; MOURA, 1996).

Apenas no ano de 2010, foram produzidas pelo Brasil 1.264.765 toneladas de pescado, um aumento de $2 \%$ em relação a 2009 , sendo 
a pesca marinha extrativista responsável por $42,4 \%$, seguida da aquicultura continental por $31,2 \%$, pela pesca extrativista continental por $19,7 \%$ e aquicultura marinha por 6,7\%, sendo o estado de São Paulo responsável por $79.262,3$ toneladas, demonstrando a importância dessa cadeia produtiva em nosso país (MPA, 2010).

Entretanto, essa cadeia produtiva pode afetar tanto o meio ambiente, como as populações e a saúde pública, através das alterações físicas, químicas e biológicas que causam no ambiente e no perfil de distribuição de enfermidades. Essa revisão objetivou difundir o conhecimento a respeito da importância das atividades da aquicultura para a saúde pública e o meio ambiente, abrangendo importantes zoonoses que vem se tornando emergentes e outros aspectos como a resistência a antibióticos decorrentes da utilização inapropriada.

\section{Interface entre aquicultura, meio ambiente e Saúde Pública}

A eutrofização ocorre devido ao aumento de matéria orgânica, fósforo e nitrogênio na água (HENRY et al., 2006; MUNDAY et al., 1992; PILLAY, 2004). Apesar de não terem sido encontradas diferenças significativas nas condições físico-química da água e nutrientes entre trechos utilizados para pisciculturas em tanques-rede e locais sem a interferência desta atividade, (CARVALHO; RAMOS, 2010). Diaz, Temporetti e Pedrozo (2001) e Hermes-Silva et al. (2004) observaram alterações na concentração de biomassa de algas, comunidades fitoplanctônicas e zooplanctônicas nessas áreas.

Segundo Kestmont (1995), os principais efeitos negativos da aquicultura sobre o meio ambiente são a alteração da temperatura da água; aumento da demanda de oxigênio e da concentração de fósforo e sólidos em suspensão; diminuição do oxigênio dissolvido; contaminação com produtos químicos; acúmulo de sedimento rico em matéria orgânica; poluição e erosão; e disseminação de doenças.

Peixes criados ou capturados em ambientes poluídos, que contenham dejetos e fezes, podem albergar não só microrganismos patogênicos (GUZMÁN et al., 2004), mas também podem estar contaminados por substâncias químicas, como os piretróides, organofosforados, avermectinas, inibidores da quitina, dioxina, metais pesados, como o mercúrio e o cobre, e uma gama de antibióticos (BURRIDGE et al., 2010; COLE et al., 2009). A utilização indiscriminada de produtos para o controle e prevenção de doenças e de defensivos agrícolas pode ter consequências diretas e indiretas no ambiente e para a saúde pública (LIUSON, 2003).

Devido à elevada densidade utilizada nas criações comerciais, aliada a uma série de outros fatores, os animais possuem maior risco de infecção por bactérias, sendo então utilizados antibióticos como tratamento terapêutico e preventivo deforma errônea e empírica, sem recomendações técnicas especializadas relativas à resistência bacteriana (GAO et al., 2012; FURUSHITA et al., 2003; PETERSEN; DALSGAARD, 2003). Esta problemática pode afetar diretamente a saúde pública, pois as bactérias do meio aquático, quando resistentes, podem influenciar a resistência de bactérias que afetam populações humanas, através de transferência genética (MARTINEZ, 2009; SAPKOTA et al., 2008). No Brasil é permitida apenas a utilização do florfenicol na aquicultura (MAPA, 2010), porém a resistência bacteriana também é observada para diversos antibióticos não permitidos, que caracteriza o não cumprimento das leis vigentes (CARNEIRO et al., 2007).

Devido ao crescimento de mercados internacionais, tradições culturais, intensificação da agropecuária, degradação ambiental, alterações demográficas e ferramentas disponíveis de controle, vêm se alterando o perfil de distribuição de enfermidades, e dentro dessas, as zoonóticas (WHO, 1995).

Algumas dessas são de origem parasitária, como a enfermidade causada pelos trematóides da família Opisthorchiidae, que causam colangite, pancreatite e colangiosarcoma, sendo determinado como fator de risco, o consumo de peixes crus ou mal cozidos e hábitos migratórios. Esta doença acomete aproximadamente 17 milhões de pessoas no mundo, principalmente na Ásia e Europa, maiores produtores mundiais de pescado. Esta distribuição é dependente da localização geográfica de caracóis hospedeiros intermediários (WHO, 2004; CHAI; MURRELL; LYMBERY, 2005). Para controle são necessárias medidas como o tratamento dos hospedeiros infectados, controle dos caracóis e educação comunitária sobre o risco presente no consumo de peixes crus (GUOQING et al., 2001 apud CHAI; MURRELL; LYMBERY, 2005). Também existem outros trematóides importantes, como os do gênero Metagonimus, Ascocotyle, Heterophyes, em que o consumo de pescado indevidamente preparado é a via de transmissão (CHAI; MURRELL; LYMBERY, 2005; OLIVEIRA et al., 2007). No Brasil, foi verificado que, de 102 pessoas que consumiram tainha crua, hospedeiro em que se observa alto índice de prevalência de infecção pelo parasita, $8,82 \%$ estavam infectadas pelas formas adultas de Ascocotyle (Phagicola) longa (CHIEFFI et al., 1990; ALMEIDA DIAS; WOICIECHOVSKI, 1994 apud OLIVEIRA et al., 2007).

Outra zoonose importante é a anisaquíase, causada pelos nematóides intestinais Anisakis simplex, Pseudoterranova decipiens e Contracaecum osculatum, em que os peixes e crustáceos são as principais fontes de infecção para humanos. No Brasil, as larvas de Anisakidae já foram encontradas em diversas espécies, 
como, por exemplo, peixe-espada (Trichiuris lepturus), anchovas (Pomatomus saltatriz), pargos (Pagrus pagrus) (GERMANO; GERMANO, 1998), peixe-porco (Aluterus monoceros) (DIAS; CLEMENTE; KNOFF, 2010) e em jundiás (Rhamdia quelen) (RUE et al., 2010). Em estudo que avaliou bacalhaus comercializados, de 11 amostras examinadas, $64 \%$ possuíam larvas de nematóides da família Anisakidae (PRADO; CAPUANO, 2006). Pereira et al. em 2000, encontraram $27,3 \%$ dos bacalhaus comerciais infectados por esse parasita na capital do estado de São Paulo. A enfermidade nunca foi diagnosticada em humanos no Brasil, que causa dor abdominal, vômito, diarréia e síndromes alérgicas.

Outra importante e emergente zoonose veiculada pelo consumo inadequado de pescado é a difilobotriose, causada pelo cestódeo Diphyllobothrium latum, parasita de peixes de água doce ou salgada, que também pode acometer humanos. O primeiro relato de Diphyllobothrium latum no Brasil ocorreu em 2004, na Bahia (SANTOS; FARO, 2005). No ano seguinte, a Secretaria de Vigilância em Saúde do Ministério da Saúde foi notificada da ocorrência de 27 casos autóctones em São Paulo, devido à ingestão de pescado cru em restaurantes japoneses. Posteriormente, em 2005, foi detectado em Brasília (LLAGUNO et al., 2008), Rio de Janeiro (TAVARES; LUQUE; BOMFIM, 2005) e Porto Alegre (MEZZARI; WIEBBELING, 2008), em que foi incriminado o consumo de sushi como via de transmissão, e em Ribeirão Preto, SP, em que foi consumido salmão cru (CAPUANO et al., 2007).

Alguns protozoários também podem acometer o consumidor, tais como Cryptosporidium sp. e Toxoplasma gondii, que foram encontrados em bivalves marinhos (CONRAD et al, 2005; HUNTER \& THOMPSON, 2005). Devido a importância dessas parasitoses, o consumidor deve ter maior cuidado ao preparar o pescado para consumo (GÓMEZ-COUSO; MÉNDEZ-HERMIDA; ARES-MAZÁS, 2006; JONES et al., 2009).

O FDA preconiza que quando o pescado será destinado ao consumo cru, deve ser congelado a $-35^{\circ} \mathrm{C}$ por 15 horas, ou $-20^{\circ} \mathrm{C}$ por pelo menos sete dias. $\mathrm{O}$ cozimento também é efetivo quando realizado utilizando o binômio tempo/temperatura, 10 minutos a $60^{\circ} \mathrm{C}$, segundo a Secretaria da Saúde do Estado de São Paulo.

As bactérias do gênero Edwardsiella $s p$ acometem peixes de água doce, causando mionecrose, abscessos hepáticos, hemorragias, ascite, ulcerações e necrose da linha lateral (NOGA, 2010). Este agente transmitido aos humanos pelo consumo de peixes infectados ou de água contaminada pode causar uma enterite grave, e em indivíduos imunosuprimidos, septicemia, celulites e mionecrose (VARTIAN; SEPTIMUS, 1990). A falta de boas práticas na cadeia produtiva do pescado é o fator determinante para o aumento da contaminação, que contribui com baixa qualidade do produto brasileiro (ALMEIDA et al., 2002).

A micobacteriose dos peixes é outra importante zoonose, tendo caráter ocupacional ou recreacional, causada pelas bactérias que não pertencem as espécies Mycobacterium leprae, M. lepraemurium ou as do complexo M. tuberculosis, sendo o M. marinum um dos agentes mais importantes (HERRON, 1995 apud ISHIKAWA, 2001). Os animais apresentam dispnéia, imobilidade, pele com lesões focais e escurecimento, nódulos, úlceras, necrose de nadadeiras, mutilações e exofltalmia (GIAVENNI et al., 1980).

Em humanos, o M. marinum pode causar lesões cutâneas denominadas "granuloma de piscina" (WOLINSKY, 1992), estando associada às atividades aquáticas como natação, pesca, navegação e aquarismo (COLLINS et al., 1985 apud ISHIKAWA, 2001). A M. fortuitum também é capaz de provocar doenças nos humanos, estando relacionada ao manuseio em aquários contaminados (BRAGG; HUCHZERMEYER; HANISCH, 1990). Também já foi encontrada micobacteriose em anfíbios e répteis (MORAES et al., 1996; RAMOS, 1997). Essa enfermidade ainda necessita de estudos para prevenção dessa doença, e preservação da sanidade aquícola e humana (ISHIKAWA, 2001).

As enfermidades causadas pelas bactérias Aeromonas hydrophila, A. sobria e A. caviae causam anorexia, letargia, exoftalmia, ascite e ulcerações e hemorragias nas nadadeiras e guelras dos peixes.. $\mathrm{O}$ aumento de carga bacteriana é devido aos elevados valores de matéria orgânica. Dessa forma o homem adquire esta doença pela contaminação de feridas e consumo da água contaminada principalmente em indivíduos imunosuprimidos (AGNEW; BARNES, 2007; NOGA, 2010). O mesmo ocorre com as espécies do gênero Vibrio sp., que podem permanecer latentes até ocorrerem fatores ambientais para seu desenvolvimento, causando anorexia, ulcerações, exoftalmia e petéquias nos animais, podendo ser transmitida pela contaminação de lesões e consumo inadequado de animais infectados (BOYLAN, 2011).

A estreptococose, Streptococcus iniae, causa hemorragias e desorientação nos peixes acometidos, e artrites, meningites e endocardites em humanos. Outro agente bacteriano importante é Erysipelothrix rhusiopathiae que causa infeccções cutâneas difusas ou localizadas e endocardite, enquanto nos mamíferos marinhos causa lesões cutâneas e septicemias agudas. Neste caso, é fundamental a manipulação do pescado congelado com luvas, pois esse microorganismo é capaz de resistir ao congelamento (BOYLAN, 2011). 
Outras bactérias zoonóticas que podem estar associadas à aquicultura incluem as do gênero Salmonella sp., Citrobacter spp., Serratia spp, Pseudomonas spp, Shigella $s p$, Staphylococcus sp., Francisella spp., Listeria spp e Clostridium spp (BOYLAN, 2011). Morita (2005) avaliou 30 pesque-pagues localizados na região metropolitana de São Paulo e detectou Escherichia coli em cerca de 23\% dos pesqueiros na época de seca, correlacionando com bactérias do gênero Salmonella spp.

\section{Considerações finais}

Muitos são os possíveis impactos decorrentes da aquicultura na saúde pública e no meio ambiente, necessitando maior atenção dos órgãos responsáveis pelo controle e fiscalização dessa cadeia produtiva. Também é fundamental a formação e capacitação adequada de profissionais capazes de atuar nessas áreas, prevenindo as enfermidades, principalmente as zoonóticas, e na resolução de problemas ambientais decorrentes de falhas técnicas e sanitárias durante todas as etapas, dede a produção até o consumidor final. Deve-se evitar o uso indiscriminado de antibióticos, utilizando-se de medidas sanitárias e nutricionais profiláticas que evitem a ocorrência de enfermidades, buscando uma cadeia produtiva mais sustentável e resiliente.

\section{Referências}

AGNEW, W.; BARNES, A. Streptococcus iniae: an aquatic pathogen of global veterinary significance and a challenging candidate for reliable vaccination. Veterinary Microbiology, v. 122, p. $1-15,2007$.

ALMEIDA, E. S.; SIGARINI, C. O.; RIBEIRO, J. N.; DELMONDES, E. C.; STELATTO, E.; ARAUJO JR., A. Características microbiológicas de "Pintado" (Pseudoplatystoma fasciatum) comercializado em supermercados e feira livre, no município de Cuiabá - MT. Revista Higiene Alimentar, v. 16, n. 99, p. 84-88, 2002.

BOYLAN, S. Zoonoses associated with fish. The Veterinary Clinics of North America. Exotic Animal Practice, v. 14, n. 3, p. 427-438, 2011.

BRAGG, R. R.; HUCHZERMEYER, H. F. A. K.; HANISCH, M. A. M. Mycobacterium fortuitum isolated from three species of fish in South Africa. Onderstepoort Journal of Veterinary Research, v. 57, p. 101-102, 1990.

BURRIDGE, L.; WEIS, J. S.; CABELLO, F.; PIZARRO, J.; BOSTICK, K. Chemical use in salmon aquaculture: a review of current practices and possible environmental effects. Aquaculture, v. 306, p. 7-23, 2010.

CAPUANO, D. M.; OKINO, M. H. T.; MATTOS, H. R. M.; TORRES, D. M. A. G. V. Difilobotríase: relato de caso no município de Ribeirão Preto, SP, Brasil. RBAC, v. 39, n. 3, p. 163-164, 2007.

CARNeiro, D. O.; FIGUeiredo, H. C. P.; Pereira Junior, D. J.; LeAL, C. A. G.; LOGATO, P. V. R. Perfil de susceptibilidade a antimicrobianos de bactérias isoladas em diferentes sistemas de cultivo de tilápia-do-nilo (Oreochromis niloticus). Arquivo Brasileiro de Medicina Veterinária e Zootecnia, v. 59, n. 4, p. 869-876, 2007.

CARVALHO, E. D.; RAMOS, I. P. A aquicultura em grandes represas brasileiras: interfaces ambientais, socioeconômicas e sustentabilidade. Boletim da Sociedade Brasileira de Limnologia, v. 38, p. 49-57, 2010.

CHAI, J. Y.; MURRELL, D.; LYMBERY, A. J. Fishborne parasitic zoonoses status and issues. International Journal of Parasitology, v. 35, p. 1233-1254, 2005.

CHIEFFI, P. P; LEITE, O. H.; DIAS, R. M. S.; TORRES, D. M. A. V.; MANGINI, A. C. S. Human parasitism by Phagicola sp (Trematoda, Heterophyidae) in Cananéia, São Paulo State, Brazil. Rev. Inst. Med. trop. S. Paulo, São Paulo, v. 32, n. 4, Aug. 1990.

COLE, D. W.; COLE, R.; GAYDOS, S. J.; GRAY, J.; HYLAND, G.; JACQUES, M. L.; DUNFORD, N. P.; SAWHNEY, C.; AU, W. W. Aquaculture: environmental, toxicological, and health issues. International Journal Enviromental Health, v. 212, p. 369-377, 2009.

CONRAD, P.; MILLER, M.; KREUDER, C. Transmission of toxoplasma: clues from the study of sea otters as sentinels of Toxoplasma gondii flow into the marine environment. International Journal of Parasitology, v. 35, p. 1155-1168, 2005.

DIAS, F. J. E.; CLEMENTE, S. C. S.; KNOFF, M. Nematoides anisaquídeos e cestoides Trypanorhincha de importância em saúde pública em Aluterus monoceros (Linnaeus, 1758) no Estado do Rio de Janeiro, Brasil. Revista Brasileira de Parasitologia Veterinária, v. 19 , n. 2, p. 94-97, 2010

DIAZ, M. M.; TEMPORETTI, P. F.; PEDROZO, F. L. Response of phytoplankton to enrichment from cage fish farm waste in Alicura reservoir (Patagonia, Argentina). Lake and Reservoir Res. Management, v. 6, p. 151-158, 2001.

FURUSHITA, M.; SHIBA, T.; MAEDA, T.; YAHATA, M.; KANEOKA, A.; TAKAHASHI, Y.; TORII, K.; HASEGAWA, T.; OHTA, M. Similarity of tetracycline resistance genes isolated from fish farm bacteriato those from clinical isolates. Appllied Enviromental Microbiology, v. 69, n. 9, p. 5336-5342, 2003.

GAO, P.; MAO, D.; LUO, W.; WANG, L.; XU, B.; XU, L. Occurrence of sulfonamide and tetracycline-resistant bacteria and resistance genes in aquaculture environment. Water Resarch, v. 46, p. 2355-2364, 2012. 
GERMANO, P. M. L.; GERMANO, M. I. S. Anisaquíase: zoonose parasitária emergente no Brasil? Higiene Alimimentar, v. 12, n. 54, p. 26-35, 1998.

GIAVENNI, R.; FINAZZI, M.; POLI. G.; GRIMALDI, E. Tuberculosis in marine tropical fishes in an aquarium. Journal of Wildlife Diseases, v. 16, n. 2, p. 161-168, 1980.

GÓMEZ-COUSO, H.; MÉNDEZ-HERMIDA, F.; ARES-MAZÁS, A. Cryptosporidium contamination in harvesting áreas of bivalve mollusks. Journal of Food Protection, v. 69 n. 1 , p. $185-190,2006$

GUZMÁN, M. C.; BISTONI, M. A.; TAMAGNINI, L. M.; GONZÁLEZ, R. D. Recovery of Escherichia coli in fresh water fish, Jenynsia multidentata and Bryconamericus iheringi. Water Research, v. 38, p. 2368-2374, 2004.

HENRY, R.; PANARELLI, E. A.; CASANOVA, S. M. C.; SIUBERTO, M. R.; AFONSO, A. A $\mathrm{O}$. Interações hidrológicas entre lagoas marginais e o rio Paranapanema na zona de sua desembocadura na represa de Jurumirim. In: NOGUEIRA, M. G.; HENRY, R.; JORCIN, A. (Ed.). Ecologia de reservatórios: impactos potenciais, ações de manejo e sistema em cascata. 2. ed. São Carlos: RiMA, 2006. p. 57-82.

HERMES-SILVA, S.; SARDÃO, B. T. N.; SANTAMARIA, F.; NUÑER, A. P. O.; ZANIBONIFILHO, E. Dinâmica do zooplâncton em uma área do Reservatório de Machadinho sob influência de cultivo em tanques-rede, rio Uruguai, Brasil. In: SIMPÓSIO: ECOLOGIA DE RESERVATÓRIOS - IMPACTOS POTENCIAIS, AÇÕES DE MANEJO E SISTEMAS EM CASCATA, 2004, Avaré. Anais... 2004. 71 p.

HUNTER, P.; THOMPSON, A. The zoonotic transmission of giardia and cryptosporidium. International Journal of Parasitology, v. 35, n. 11/12, p. 1181-1190, 2005

ISHIKAWA, C. M.; MATUSHIMA, E. R.; SOUZA, C. W. O.; TIMENETSKY, J.; RANZANIPAIVA, M. J. T. Micobacteriose em peixes. Boletim do Instituto da Pesca, São Paulo, v 27, n. 2, p. 231-242, 2001.

JONES, J. L.; DARGELAS, V.; ROBERTS, J.; PRESS, C.; REMINGTON, J. S.; MONTOYA, J. G. Risk factors for Toxoplasma gondii infection in the United States. Clinical Infectious Diseases, v. 49, p. 878-884, 2009.

KESTMONT, P. Different system of carp production and their impacts on the environment. Aquaculture, Amsterdam, v. 129, p. 347-372, 1995.

LIUSON, E. Pesquisa de coliformes totais, fecais e Salmonella spp em tilápias de pesqueiros da região metropolitana de São Paulo. 2003. 94 f. Dissertação (Mestrado em Medicina Veterinária) - Faculdade de Medicina Veterinária e Zootecnia, Universidade de São Paulo, São Paulo, 2003.

LLAGUNO, M. M.; ESCALANTE, J. C.; WAIKAGUL, J.; FALEIROS, A. C. G.; CHAGAS, F.; CASTRO, C. Diphyllobothrium latum infection in a non-endemic country: case report. Revista da Sociedade Brasileira de Medicina Tropical, v. 41, n. 3, p. 301-303, 2008.

MAPA. MINISTÉRIO DA AGRICULTURA E PECUÁRIA. Compêndio de produtos veterinários. [2012]. Disponível em: <http://www.cpvs.com.br/cpvs/index.html>. Acesso em: 22 out. 2012.

MAPA. MINISTÉRIO DA PESCA E AQUICULTURA. Boletim Estatístico da Pesca e Aquicultura, 2010. Disponível em: <http://www.mpa.gov.br/images/Docs/Informacoes_e_Estatisticas/ Boletim\%20Estat\%C3\%ADstico\%20MPA\%202010.pdf . Acesso em: 16 jul. 2012.

MARTINEZ, J. L. Environmental pollution by antibiotics and by antibiotic resistance determinants. Environmental Pollution, v. 157, p. 2893-2902, 2009.

MEZZARI, M. D. A.; WIEBBELING, A. M. P. Diphyllobothriasis in Southern Brazil, Clinical Microbiology Newsletter, v. 30, p. 28-29, 2008.

MORAES, J. R. E.; TORRES, H. A.; MARTINS, M. L.; SOUZA, V. N.; MORAES, F. R. Tuberculose em Rana catesbeiana (Shaw, 1802), em ranários comerciais diagnosticados pelo Centro de Aqüicultura da UNESP. In: ENCONTRO BRASILEIRO DE PATOLOGISTAS DE ORGASNIMOS AQUÁTICOS, 4., 1996, Pirassununga. Resumos... São Paulo: ABRAPOA, 1996. p. 28. MORITA, M. Avaliação da qualidade sanitária e ocorrência de Aeromonas spp. em lagoas de pesque-pague da Região Metropolitana de São Paulo. 2005. 119 f. Tese (Mestrado) - Faculdade de Saúde Pública, Universidade de São Paulo, São Paulo, 2005.

MUNDAY, B. W.; ELEFTHERIOU, A.; KENTOURI, M.; DIVANACH, P. The interactions of aquaculture and the environment: a bibliographical review. Bruselas: Commission of the European Communities, Directorate General for Fisheries, 1992. 325 p.

NOGA, E. Diagnoses made by bacterial culture of kidney or affected organs. In: NOGA, E. (Ed.). Fish disease, diagnosis and treatment. 2. ed. Ames (IA): Iowa State University Press, 2010. p. 185-90.

OLIVEIRA, S. A.; BLAZQUEZ, F. J. H.; ANTUNES, S. A.; MAIA, A. A. M. Metacercárias de Ascocotyle (Phagicola) longa Ransom, 1920 (Digenea: Heterophyidae), em Mugil platanus, no estuário de Cananéia, SP, Brasil. Ciencia Rural, v. 37, n. 4, p. 1056-1059, 2007.

PEREIRA, A. D.; ATUI, M. B.; TORRES, D. M. A. G. V.; MANGINI, A. C.; ZAMBONI, C. Q. Incidência de parasitos da família Anisakidae em bacalhau (Gadus morhua) comercializado no Estado de São Paulo. Revista do Instituto Adolfo Lutz, v. 59, p. 45-49, 2000.

PETERSEN, A.; DALSGAARD, A. Species composition and antimicrobial resistance genes of Enterococcus spp, isolated from integrated and traditional fish farms in Thailand. Enviromental Microbiology, v. 5, n. 5, p. 395-402, 2003.

PILLAY, T. V. R. Aquaculture and the environment. 2. ed. Oxford: Blackwell Publishing, 2004. 94 p.

PRADO, S. P. T.; CAPUANO, D. M. Relato de nematoides da família Anisakidae em bacalhau comercializado em Ribeirão Preto, SP. Revista Sociedade Brasileira de Medicina Tropical, v. 39, n. 6, p. 580-581, 2006.

QUEIROZ, J. F.; MOURA, E. V. Aquacultura e recursos pesqueiros: alternativa para o desenvolvimento sócio-econômico do Rio Grande do Norte. Caderno Ciência \& Tecnologia, v. 13, n. 2, p. 195-224, 1996.

RAMOS, M. C. C. Avaliação de aspectos morfológicos, histoquímicos, imunohistoquímicos e ultra-estruturais do processo inflamatótio crônico, induzido experimentalmente pela inoculação de Mycobacterium marinum vivo e morto pelo calor, em tartarugas tracajá Podocnemis unifilis, (Troschel, 1848). 1997. 135 p. Tese (Doutorado) - Faculdade de Medicina Veterinária e Zootecnia, Universidade de São Paulo, São Paulo, 1997.

RUE, M. L.; CEOLIN, L. V.; GABRIEL, C. C.; BALDISSEROTTO, B.; BECKER, A. G.; ALMEIDA, F. M.; JUNIOR, J. P. Risco de zoonose por parasitos do trato digestores de jundiás (Rhamdia quellen) coletados em reservatórios de água da região central do Rio Grande do Sul. Revista Saúde (Santa Maria), v. 36, n. 2, p. 79-81, 2010.

SANTOS, F. L. N.; FARO, L. B. The first confirmed case of Diphyllobothrium latum in Brazil. Memorial Instituto Oswaldo Cruz, v. 100. p. 585-586, 2005.

SAPKOTA, A.; SAPKOTA, A. R.; KUCHARSKI, M.; BURKE, J.; MCKENZIE, S.; WALKER, P.; LAWRENCE, R. Aquaculture practices and potential human health risks current knowledge and future priorities. Enviromental International, v. 34, p. 1215-1226, 2008.

TAVARES, L. E. R.; LUQUE, J. L.; BOMFIM, T. C. B. Human diphyllobothriasis: reports from Rio de Janeiro, Brazil. Revista Brasileira Parasitologia Veterinária, v.14, n. 2, p. 85-87, 2005.

VARTIAN, C.; SEPTIMUS, E. Soft-tissue infection caused by Edwardsiella tarda and Aeromonas hydrophila. Journal Infectious Diseases, v. 161, n. 4, p. 816, 1990.

WHO. WORLD HEALTH ORGANIZATION. Control of foodborne trematode infections. World Health Organization Technical Report Series, n. 849, p. 1-157, 1995.

WHO. WORLD HEALTH ORGANIZATION. Report of Joint WHO/FAO workshop on food-borne trematode infections in Asia, Ha Noi, 2002, Vietnam. Manila, Philippines: WHO; WPRO, 2004. p. 1-58. (Report Series Number: RS/2002/GE/40(VTN)).

WOLINSKY, E. Mycobacterial diseases other than tuberculosis. Clinical Infectious Diseases, v. 15, p. 1-121, 1992. 